\title{
Quantitative Correlation of Optic Nerve Pathology with Ocular Pressure and Corneal Thickness in the DBA/2 Mouse Model of Glaucoma
}

\author{
Denise M. Inman, ${ }^{1}$ Rebecca M. Sappington, ${ }^{2}$ Philip J. Horner, ${ }^{1}$ and David J. Calkins ${ }^{2}$
}

Purpose. To investigate quantitatively the relationships between elevated intraocular pressure (IOP), axonal loss, and corneal thickness in the DBA/2 mouse model of glaucoma, to understand better how these factors contribute to disease progression.

Methods. IOP was measured with a handheld tonometer (Tono-Pen; Medtronic Solan, Jacksonville, FL) in 195 to 446 eyes of mice 2 to 10 months of age sampled from a colony of $400 \mathrm{DBA} / 2$ mice. From a group of 24 eyes at 4, 9, and 10 months of age, correlations were determined between the density and number of RGC axons, corneal thickness, and IOP.

Results. Mean IOP levels in the colony were 15 to $16 \mathrm{~mm} \mathrm{Hg}$ at 2 months of age and rose almost linearly at a rate of $0.9 \mathrm{~mm}$ $\mathrm{Hg} / \mathrm{mo}$ before reaching 22 to $23 \mathrm{~mm} \mathrm{Hg}$ at 10 months. Both the density and number of axons decreased with increasing average lifetime IOP. IOP variation within age groups strongly correlated with density. Age-matched mice with lower mean IOP had greater preservation of axons in the optic nerve. Elevated IOP was accompanied by increased corneal thickness at the limbus. Surprisingly, corneal thickness was a strong predictor of axonal density $\left(r^{2}=-0.75\right)$, regardless of age.

Conclusions. IOP increased with age in most, but not all, $\mathrm{DBA} / 2$ mice. In age-matched mice, differences in IOP corresponded to differences in axonal density and number. In young mice with elevated IOP, the loss of axons resembled that of older animals with similar IOP. Whether corneal thickness is a byproduct of elevated IOP remains unknown, but it may be useful as an index of optic nerve degeneration. (Invest Ophthalmol Vis Sci. 2006;47:986-996) DOI:10.1167/iovs.05-0925

$\mathrm{E}^{\mathrm{t}}$ levated intraocular pressure (IOP) is a primary risk factor for development of glaucomatous optic neuropathy, ${ }^{1,2}$ which results in a large-scale loss of RGC axons. ${ }^{3}$ To understand better the role of IOP in glaucomatous loss of vision, it is important to determine empirically how departures from normal IOP and chronic elevations in IOP correlate with patho-

From the ${ }^{1}$ Department of Neurosurgery, University of Washington, Seattle, Washington; and the ${ }^{2}$ Department of Ophthalmology and Visual Sciences, Vanderbilt University Medical Center, Nashville, Tennessee.

Supported by the Catalyst for a Cure consortium funded by the Glaucoma Research Foundation and the Kirsch Foundation (DJC, PJH). DJC was also supported by a Wasserman Award and Challenge Grant from Research to Prevent Blindness, Inc.

Submitted for publication July 18, 2005; revised October 10 and 26, 2005; accepted December 12, 2005.

Disclosure: D.M. Inman, None; R.M. Sappington, None; P.J. Horner, None; D.J. Calkins, None

The publication costs of this article were defrayed in part by page charge payment. This article must therefore be marked "advertisement" in accordance with 18 U.S.C. $\$ 1734$ solely to indicate this fact.

Corresponding author: Denise M. Inman, University of Washington, Department of Neurosurgery, Harborview Research \& Training, 300 Ninth Avenue, Room 327, Box 359655, Seattle, WA 98104; inmand@u.washington.edu. logic changes in the optic nerve. It is also important to determine whether other factors in conjunction with IOP also predict the loss of these axons. For patients with glaucoma, good diagnosis through IOP measurement is complicated by many factors, including corneal thickness. When not corrected for, central corneal thickness can significantly affect IOP measurement ${ }^{4-7}$ and can lead to overestimates of IOP and misdiagnosis of ocular hypertension in patients with thicker corneas and underestimates of IOP and misdiagnosis of normal-tension glaucoma in patients in whom the more appropriate diagnosis would be primary open-angle glaucoma (POAG). ${ }^{4}$ Central corneal thickness has been identified as a powerful predictor of the development of POAG in patients with ocular hypertension: the thinner the cornea, the greater the risk of POAG. ${ }^{2}$ However, in acute primary angle-closure glaucoma (PACG), patients with the thickest corneas often experience the most catastrophic vision impairment. ${ }^{8}$

Animal models of glaucoma, such as the DBA/2 mouse, can allow for unequivocal comparison of multiple factors related to the mechanisms of axon loss in glaucoma. In the DBA/2, the development of increased IOP coincides with various histopathological features that indicate disease progression. ${ }^{9}$ By 6 months of age, DBA/2 mice exhibit atrophy of the iris-pigment epithelium, corneal opaqueness, pupillary borders thickened with phagocytic macrophages, peripheral anterior synechiae, and ciliary body atrophy. ${ }^{9,10}$ Studies indicate that IOP is significantly raised in DBA/2 mice between 6 and 9 months of age. ${ }^{9}$ Correspondingly, ultrastructural evidence of ganglion cell apoptosis has been observed by 6 months, and swollen axons with membrane aggregates appear between 8 and 11 months, when roughly half the DBA/2 mice demonstrate optic nerve atrophy. ${ }^{11}$ Finally, significant ganglion cell loss has been documented in mice between 12 and 15 months of age. ${ }^{12}$ Because the DBA/2 model mirrors many of the ocular changes observed in human glaucoma, it is a useful system for probing the events related to ganglion cell degeneration. However, despite broadening usage, the significance of IOP in establishing axonal loss and RGC death in the DBA/2 mouse is only qualitatively understood. For example, individual IOP data have not been available for mice in which axon density in the optic nerve is also known. A more quantitative analysis of the DBA/ 2 phenotype based on longitudinal IOP information should improve the ability to extract mechanistic information from this model. One important step is prospectively choosing mice for experiments based on a specific disease-related parameter such as IOP.

Herein, we describe IOP measurements obtained longitudinally in our colony of DBA/2 mice with a handheld tonometer (Tono-Pen XL; Medtronic Solan; Jacksonville, FL), which has been used successfully to measure IOP in rats ${ }^{13,14}$ and mice. ${ }^{15,20}$ We demonstrate correlations between these measurements, axonal loss, and corneal thickness in individual animals. We found that IOP begins to increase much earlier than has been reported in the DBA/2 mouse, with the occasional young mouse demonstrating elevations. By comparing pathology across animals, we find that the loss of RGC axons in the optic nerve correlates strongly with mean lifetime IOP, so 
that even small differences in IOP correlate with differences in the number of axons. Of interest is that corneal thickness is a strong predictor of axonal loss, regardless of age, with a threefold increase in thickness correlating to a threefold drop in axon density.

\section{Methods}

\section{Mice}

These experiments adhered to the ARVO Statement for the Use of Animals in Ophthalmic and Vision Research and were approved by the Institutional Animal Care and Use Committee at the University of Washington. DBA/2 mice were initially obtained from Jackson Laboratories (Bar Harbor, ME) and bred in a specific pathogen-free facility at Harborview Research and Training, University of Washington. Mice were maintained in a 12-hour light-dark cycle with standard rodent chow available ad libitum.

\section{Genotyping}

DBA/2 mice have two ocular phenotypes, iris stromal atrophy (ISA) and iris pigment dispersion (IPD), ${ }^{16}$ that are caused by mutations in the Tyrp1 and Gpnmb genes, respectively. Tyrp1 (tyrosinase-related protein 1) has two missense mutations that cause amino acid substitutions (Cys110Tyr and Arg326His) and alter protein folding, to yield a nonfunctional protein product. ${ }^{17}$ The second missense mutation (nt1151 of the mouse mRNA; GI:13654240) eliminates a restriction site, a situation that allowed us to use PCR to amplify (from genomic DNA) a sequence spanning the restriction site, digest the sequence with BbsI (New England BioLabs, Beverly, MA), and use the resultant bands to distinguish between non-DBA/2 and DBA/2 mice. Gpnmb, (glycoprotein transmembrane $\mathrm{nmb}$ ), the gene responsible for the IPD phenotype, has a point mutation $(\mathrm{C} \rightarrow \mathrm{T})$ at nt547 of the mouse mRNA (GI:315429906) that creates a premature stop codon, yielding a truncated protein on translation. ${ }^{17}$ The point mutation also inserts a PvuII (New England BioLabs) restriction site in the mRNA $^{17}$ which was used to digest a sequence amplified by PCR from genomic DNA, leaving fragments that unambiguously identified DBA/2 mice from non-DBA/2 mice, whose PCR product was left intact. Primers used to amplify a portion of the Tyrp1 gene were 5'-GCATTGCTCAGACCTATAGATATTC-3' (forward) and 5'-CAAAACACCAATTTTGTTTACTTGC-3' (reverse); for the Gpnmb gene, the primers were 5'-CCACTGAGCATTTGGAGACA-3' (forward) and 5'-TGGATGGAAGAAATGGAGCT-3' (reverse).

Genomic DNA was isolated from DBA/2 ear punch tissue using a DNA isolation kit (Puregene D-7000A; Gentra Systems, Minneapolis, $\mathrm{MN}$ ). One nanogram of genomic DNA was placed in a tube with PCR master mix (Taq DNA polymerase, dNTPs, $\mathrm{MgCl}_{2}$ and buffers; Promega, Madison, WI), and forward and reverse primers for Tyrp 1 or $G$ pnmb were placed in a thermocycler $\left(40\right.$ cycles of $94^{\circ} \mathrm{C}$ for 1 minute, $55^{\circ} \mathrm{C}$ for 30 seconds, and $72^{\circ} \mathrm{C}$ for 30 seconds; model Px2; Thermo Hybaid, Franklin, MA). Restriction digest took place with $10 \mu \mathrm{L}$ of PCR product, $1 \mathrm{U}$ of restriction enzyme, BSA, and $2 \mu \mathrm{L}$ of $10 \times$ buffer in a $37^{\circ} \mathrm{C}$ water bath for 1 hour. Digest products were run on a $2 \%$ agarose gel and then photographed. Select DBA/2 mice from the colony maintained in the Horner laboratory were genotyped to ensure that the mice were homozygous for ISA and IPD. ${ }^{17}$ The ISA and IPD genotypes were confirmed in every DBA/2 tested. A typical genotyping result is shown in Figure 1.

\section{Tonometer Measurements of IOP}

IOP was measured with the Tono-Pen XL (Medtronic Solan). In adapting to the mouse a portable tonometer developed for humans, we discarded the latex cover protecting the microstrain gauge tip from cross-contamination, to avoid interfering with corneal contact. Each DBA/2 mouse was anesthetized (Avertin, 1.3\% tribromoethanol, $0.8 \%$ tert-amyl alcohol) and positioned on its side with the eye facing

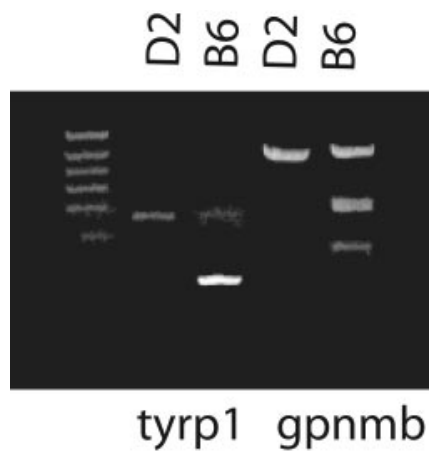

Figure 1. Genotyping results for the typical DBA/2 colony member. The amplified sequence of the Tyrp1 gene, after restriction digest with BbsI, showed two bands in a mouse with the wild-type gene (lane 2: $\mathrm{C} 57 \mathrm{Bl} / 6$ ) and one band in the DBA/2 mouse (lane 1). The mutation in the DBA/2 mouse removed the restriction site so that the PCR product did not get digested. After restriction digest with PvuII, the Gpnmbamplified sequence yielded one band for the wild-type allele in the C57Bl/6 mouse (lane 3) and two bands in the DBA/2 mouse with the mutant allele (lane 4 ). The mutation sustained in the Gpnmb sequence in DBA/2 mice had a PvuII restriction site insertion.

upward and head supported by a stack of sterile gauze. Proparacaine $(0.5 \%$ proparacaine hydrochloride ophthalmic solution; Bausch \& Lomb, Tampa, FL) was applied to the eye before and sometimes during IOP measurement, to maintain corneal moisture, which is vital in obtaining consistent measurements of IOP. Without the latex cover, the tonometer was applanated against the cornea, directly over the anterior chamber, using a quick, short movement. The mouse was positioned such that the force applied during applanation directed the eye straight back into the orbit. Generally, the IOP measurements from one eye were completed in 2 to 3 minutes.

By recommendation (McKinnon S, personal communication, March 2003) 20 tonometer measurements were taken and recorded in each eye. The automatic average IOP measurement generated by the tonometer after three applanations was not included in the recorded measurements. The decision to collect 20 measurements per mouse eye was supported by an analysis of the colony IOP data over 3 months. Using a 95\% confidence interval of IOP measurement from the colony, measurements outside the confidence interval were excluded from the IOP average calculated for that eye, and it was found that the new calculated average (having eliminated 1 to 5 measures per eye) did not differ significantly from the original (data not shown). This suggests that 20 measures per eye were statistically powerful, and we chose to continue with that number. The working range of the Tono-Pen is five to $80 \mathrm{~mm} \mathrm{Hg}$ (Medtronic Solan); therefore, pressures obtained outside this range were discarded. We measured IOP in mice between 2 and 10 months of age, measuring the same mice for as long as possible, and also adding new groups to the cohort as they reached maturity. This process resulted in the following number of eyes being measured per age (months): $2(n=195), 3(n=446), 4(n=412), 5(n=401), 6$ $(n=357), 7(n=336), 8(n=332), 9(n=269)$, and $10(n=69)$. For the mice used in our histopathological studies (Table 1) we calculated the average IOP over the months for which we obtained tonometer measurements.

\section{Histopathology}

We chose five mice each at 9 and 10 months of age ("old low-IOP" group and "old high-IOP" group, respectively) for correlative studies of IOP and optic nerve pathology. We added two 4-month animals with elevated IOPs for comparison, the "young high-IOP" group. An additional four animals at 4 months of age were chosen to represent a nondiseased state-the "young normal" group-because they demonstrated an absence of any external sign of the disease generally associated with the DBA/2, such as iris atrophy, pigmentary dispersion, or 
TABLE 1. Summary of DBA/2 Mice for Histological Analysis

\begin{tabular}{cccccc}
\hline DBA/2 & Eye(s) & $\begin{array}{c}\text { Age } \\
\text { (mo) }\end{array}$ & $\begin{array}{c}\text { Age for IOP } \\
\text { (mo) }\end{array}$ & $\begin{array}{c}\text { Corneal } \\
\text { Measures }\end{array}$ & Axon Counts \\
\hline 1 & $\mathrm{R}$ & 4 & None* $^{*}$ & Yes & Yes \\
2 & $\mathrm{R}$ & 4 & None* $^{*}$ & Yes & Yes \\
3 & $\mathrm{R}$ & 4 & None* & Yes & Yes \\
4 & $\mathrm{R}$ & 4 & None* $^{*}$ & Yes & Yes \\
5 & $\mathrm{~L}$ & 4 & 4 & Yes & Yes \\
6 & $\mathrm{~L}$ & 4 & 4 & Yes & Yes \\
7 & $\mathrm{~L}+\mathrm{R}$ & 9 & $6,8,9$ & Yes & Yes \\
8 & $\mathrm{~L}+\mathrm{R}$ & 9 & $6,8,9$ & No & Yes \\
9 & $\mathrm{R}$ & 9 & $6,8,9$ & Yes & Yes \\
10 & $\mathrm{~L}$ & 9 & $6,8,9$ & Yes & Yes \\
11 & $\mathrm{~L}+\mathrm{R}$ & 9 & $6,8,9$ & Yes & R only \\
12 & $\mathrm{~L}+\mathrm{R}$ & 10 & $9-10$ & R only & No \\
13 & $\mathrm{~L}+\mathrm{R}$ & 10 & $9-10$ & R only & R only \\
14 & $\mathrm{~L}+\mathrm{R}$ & 10 & $9-10$ & Yes & Yes \\
15 & $\mathrm{~L}+\mathrm{R}$ & 10 & $7-10$ & No & L only \\
16 & $\mathrm{~L}+\mathrm{R}$ & 10 & $7-10$ & No & \\
\hline
\end{tabular}

* Animals demonstrated an absence of any external features of disease typical of DBA/2 mice with elevated IOP.

corneal opaqueness $^{9}$ (see the introduction). A post hoc analysis supported this choice, since these animals invariably demonstrated thin, intact corneas, high axonal density, and normal myelination in the optic nerve (described later). These $16 \mathrm{DBA} / 2$ mice were euthanatized with $300 \mathrm{mg} / \mathrm{kg}$ sodium pentobarbital and then perfused with $4 \%$ paraformaldehyde (PFA) in 0.1 M phosphate buffer (PB; pH 7.4). From these animals, 24 eyes with optic nerves attached were carefully dissected from the skull. The anterior segment was separated from the posterior eye cup. Both were postfixed for 1 hour in 4\% PFA and thoroughly washed in $0.1 \mathrm{M} \mathrm{PB}$. The optic nerves were separated from the eye cups so that the two could be processed separately. The limbic region of the anterior segment and a 2 - to $3-\mathrm{mm}$ section of optic nerve proximal to the globe were isolated and prepared for embedding and semithin sectioning as previously described. ${ }^{18,19}$ From these tissues, we measured corneal thickness at the limbus and axonal density in the optic nerve. A summary of the use of these animals and the number of longitudinal IOP measurements for each is included in the following sections.

\section{Axon Counts}

To obtain counts of ganglion cell axons, three to four semithin sections each 1- to $2-\mu \mathrm{m}$-thick were selected from each nerve based on their contrast. Using $100 \times$ oil-immersion, differential interference contrast optics, photomicrographs of each section were collected from 20 to 25 random, nonoverlapping positions with a microscope (Provis AX70; Olympus, Melville, NY) equipped with a motorized $x-y-z$ stage and a digital charge-coupled device (CCD) camera. Because the effective magnification through the CCD camera was more than $1000 \times$, we ensured through the high number of photomicrographs and our sampling algorithm that the entire surface area of the nerve was represented in the sample. Each micrograph was contrast- and edge-enhanced by using macro routines written in an image-analysis software package (ImagePro; Media Cybernetics, Silver Spring, MD). An additional routine was used to identify and count each axon for which a myelin sheath could be identified and to calculate the sampling area of the micrograph. We used this information to calculate the axonal density for each micrograph. For each sample of nerve, axon density was calculated as the mean across the random micrographs. We also measured the cross-sectional area of each nerve and used this with axonal density, to estimate the total number of axons.

\section{Statistical Analysis}

All data in the text are given as the mean \pm SEM, except when indicated otherwise. Error bars in all graphs and histograms represent bidirectional SEM. We used the regression wizard feature of the dataanalysis software (Sigmaplot; SPSS, Inc., Chicago, IL) to find the theoretical curve that best describes mean colony IOP as a function of age and to fit regression lines to the various histologic measures, both by minimizing the sum of squared errors. Correlation coefficients and corresponding probabilities were calculated with the statistical toolbox of another data-analysis program (Excel; Microsoft, Redmond, WA). Statistical comparisons between data sets across multiple independent variable values (e.g., IOP for males versus females) or between multiple groups of animals for a single independent variable were made with one-way analysis of variance (ANOVA).

\section{Results}

\section{Significant IOP Increase in the DBA/2 Mouse}

We represent in Figure 2A the average Tono-Pen (Medtronic Solan) measurements of IOP in mice in our colony. These data demonstrate IOPs that began at 15 to $16 \mathrm{~mm} \mathrm{Hg}$ at 2 months of age and rose approximately linearly to 22 to $23 \mathrm{~mm} \mathrm{Hg}$ at 10 months of age. Although the best-fitting curve to the colony's average IOP over time is a four-parameter sigmoidal with a $y$-intercept of $14.10 \mathrm{~mm} \mathrm{Hg}$, the data are also very well described by a linear regression of slope $0.9 \mathrm{~mm} \mathrm{Hg} / \mathrm{mo}$. A post hoc test for linear trend is significant $(P<0.0001)$, consistent with IOP increasing over time. Although there have been reports of differences in IOP between male and female DBA/2 mice, with females demonstrating accelerated IOP increases, our measurements in Figure $2 \mathrm{~A}$ indicate statistical identity between males and females, with no systematic tendency for higher IOP for one sex over the other $(P=0.74)$.

In Figure $2 \mathrm{~B}$, the average lifetime IOP of each animal used in our histopathology studies is plotted at the animal's terminal age (Table 1). The IOPs for the entire colony are repeated for comparison. From these data, it is clear that the 9-month mice used in this study tended to have lower than average IOP $(18-21 \mathrm{~mm} \mathrm{Hg})$. These mice were intentionally chosen to compare to the mice at 10 months of age, whose IOP spanned a considerable range, both below- and above-average (20-27 $\mathrm{mm} \mathrm{Hg}$ ). Because the animals in the 9- and 10-month groups were generally only 2 to 4 weeks apart in age, this choice allowed us a wide range of IOP with which to probe for contribution of IOP to disease progression. Indeed, the mean IOP for the $9-(19.4 \pm 0.3 \mathrm{~mm} \mathrm{Hg})$ and $10-(22.5 \pm 0.7 \mathrm{~mm}$ 

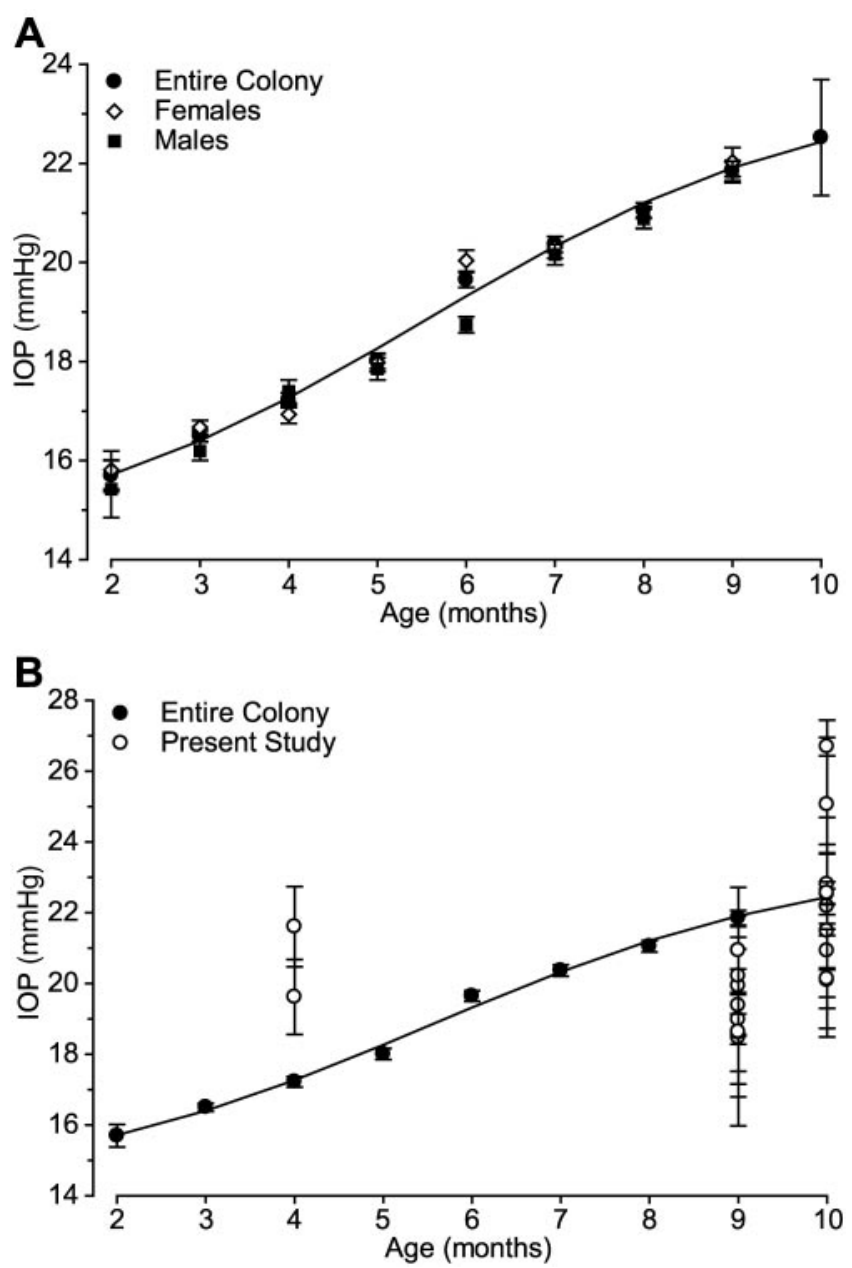

Figure 2. (A) Tono-Pen measurements of IOP from our DBA/2 mouse colony of 2 to 10 months of age, showing how IOP compared in females and males. Each point represents the mean \pm SEM of measurements from 69 to 446 eyes. The greater variability at 10 months of age is due to the relatively small sample size (69 eyes). The solid curve is a four-parameter sigmoidal function that describes best the dependence of IOP on age. IOP increased at an approximate rate of $0.9 \mathrm{~mm}$ $\mathrm{Hg} / \mathrm{mo}$. (B) Mean IOP $\pm \mathrm{SEM}$ plotted at the final age in 12 mice included in our ocular histopathology studies in comparison with the colony mean IOP.

Hg)-month-old groups are significantly different $(P=0.001)$ The two 4-month-old mice we added for comparison had higher than average IOP for their age (19-22 $\mathrm{mm} \mathrm{Hg})$. As mentioned in the Methods section, to ease description of the findings across these mice, the 4-month-old DBA/2 mice with high IOP will be referred to as "young high-IOP" mice. The 9and 10-month DBA/2 mice will be referred to as "old low-IOP" and "old high-IOP," respectively, to reflect the distinction of low or high IOP in these mice that were roughly the same age.

Figure 2B shows a colony-wide IOP increase of $7 \mathrm{~mm} \mathrm{Hg}$ from 2 to 10 months of age, a statistically significant increase. There is a range of IOP within each age group. Figure $3 \mathrm{~A}$ shows the distribution of individual IOP measurements across animals for three pooled age groups: 2 to 4,5 to 7 , and 8 to 10 months. This histogram demonstrates the shift toward higher IOP with age. This shift, given the large sample size, is significant: the ANOVA statistic is $433(P \ll 0.001)$. Even when IOP measurements are compared month-to-month, the differences remain significant (for example, 2 vs. 3 months, $P=0.003 ; 4$ vs. 5 months, $P=0.0002$; 6 vs. 7 months, $P=0.001$; and 8 vs. 9 months, $P=0.002$ ). The only pair-wise comparison that is not statistically significant is 9 versus 10 months $(P=0.55)$, but this may be due to the relatively small size of the 10-month sample (see the Methods section). The distributions in Figure $3 \mathrm{~A}$ also show that, whereas IOP tended to increase in the colony, it did not necessarily do so in every animal. Our colony contained mice with a large range of IOP at each age. For example, although the fraction of eyes with IOP $<15 \mathrm{~mm} \mathrm{Hg}$ decreased considerably from 2 to 4 months of age, there remained a population $(2 \%-17 \%)$ of mice with IOP $<15 \mathrm{~mm}$ $\mathrm{Hg}$ in the 5- to 10-month-old animals (Fig. 3B, top). Similarly, whereas the fraction of eyes with IOP $>20 \mathrm{~mm} \mathrm{Hg}$ increased as expected with age, there was a small fraction ( $8 \%-23 \%)$, even from the youngest animals (Fig. 3B, bottom) with IOP $>20 \mathrm{~mm}$ $\mathrm{Hg}$.

\section{Subtle Changes in Pressure and Axonal Loss in the Optic Nerve}

Next, we focused our efforts on correlating IOP with multiple histopathological features of the DBA/ 2 mouse. We began by asking how axonal loss in the DBA/2 optic nerve varies with differences in mean lifetime IOP, using the DBA/2 mice summarized in Table 1 . Figure $4 \mathrm{~A}$ shows a cross-section through the nerve of a mouse from the young normal group lacking any external disease features typical of the DBA/2 (see the Methods section). The axons are packed densely $\left(5.4 \times 10^{5}\right.$ axons/ $\mathrm{mm}^{2}$ ), with almost all demonstrating a completely intact myelin sheath. In Figure $4 \mathrm{~B}$, the nerve of a young high-IOP animal (mean IOP: $21.60 \pm 1.14 \mathrm{~mm} \mathrm{Hg}$ ) shows $35 \%$ fewer axons $\left(3.5 \times 10^{5}\right.$ axons $\left./ \mathrm{mm}^{2}\right)$ compared with the nerve in Figure 4A. The nerve of an old low-IOP animal (mean IOP: $19.38 \pm 2.22$ $\mathrm{mm} \mathrm{Hg}$; Fig. 4C) had axon density $\left(6.2 \times 10^{5}\right.$ axons $\left./ \mathrm{mm}^{2}\right)$ comparable to that of the young normal mouse. Finally, an old high-IOP DBA/2 (mean IOP: $25.06 \pm 2.38 \mathrm{~mm} \mathrm{Hg}$; Fig. 4D) had a severely depleted nerve with greater than $50 \%$ loss of myelinated axons $\left(2.6 \times 10^{5}\right.$ axons $\left./ \mathrm{mm}^{2}\right)$ compared with the young normal and old low-IOP mice.

The graph in Figure 5A shows how mean axonal density varied across nerves in the animals used to correlate IOP with histopathology (Table 1). Optic nerve axon density was approximately $25 \%$ less in the old high-IOP animals than in the old low-IOP mice $(P=0.004)$, and young high-IOP nerves had axon density nearly $40 \%$ lower than the old low-IOP nerves $(P=0.001)$. Despite only a small difference in age, the old high-IOP mice have significantly greater lifetime IOP than the old low-IOP mice. IOP measurements for the young high-IOP mice were significantly greater than IOP for the old low-IOP mice. The IOP relationships among mice correspond to the axon density findings: high IOP indicates lower axon density, regardless of age. The scatterplot in Figure 5B demonstrates that mean lifetime IOP was an excellent predictor of axonal density $\left(r^{2}=-0.72, P \ll 0.001\right)$. Old high-IOP animals tended to have higher IOP than the old low-IOP mice (see also Fig. 2B) and had accordingly reduced axon density. Even within the old low-IOP and old high-IOP groups, slightly increased mean lifetime IOP resulted in reduced axonal density. The apparent difference in mean axon density between the young high-IOP and old high-IOP groups in Figure 5A was not significant $(P=$ $0.39)$, nor were their IOPs dramatically different $(P=0.27$; Fig. $5 \mathrm{~B})$, despite the 6-month difference in age.

The total number of axons in each optic nerve was estimated using the nerve cross-sectional area and axon density as found in Figure 5. For this calculation, the mean density calculated from the high-magnification random sampling was assumed to represent a uniform density for each group, which is not necessarily the case. We found little variability in nerve area, which spanned a narrow range of 0.07 to $0.11 \mathrm{~mm}^{2}$ for 
A

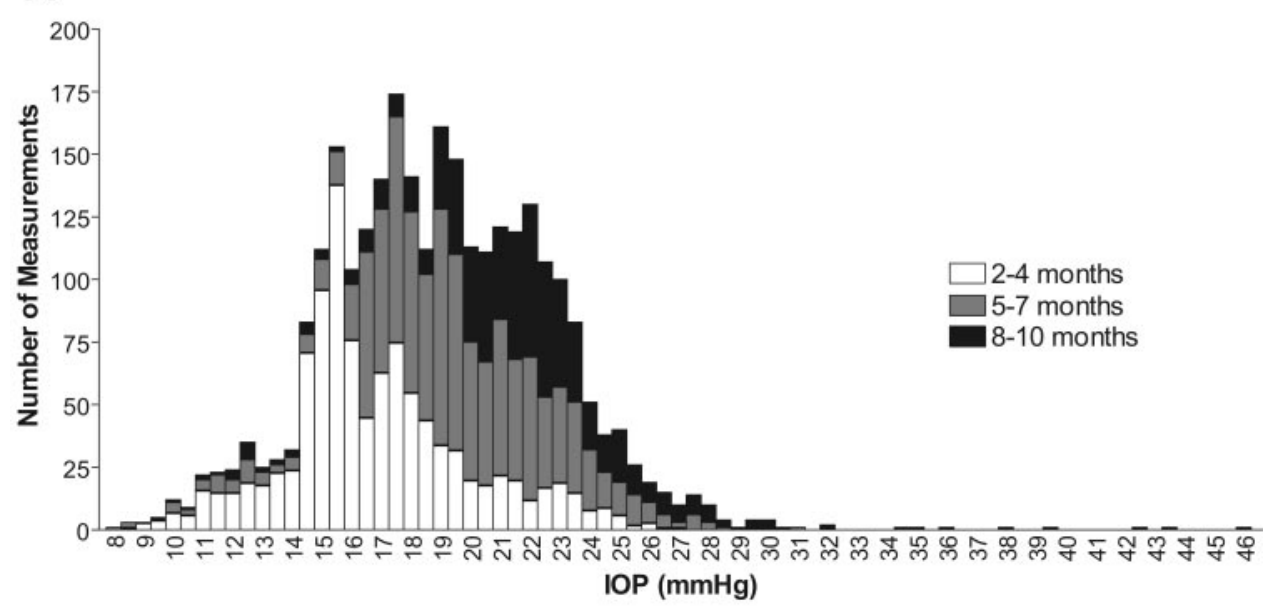

Figure 3. (A) Distributions of IOP measurements across eyes of mice aged 2 to 4,5 to 7 , and 8 to 10 months demonstrated a significant shift in IOP with increasing age (ANOVA; $P \ll 0.001$ ). Mean \pm SEM

B
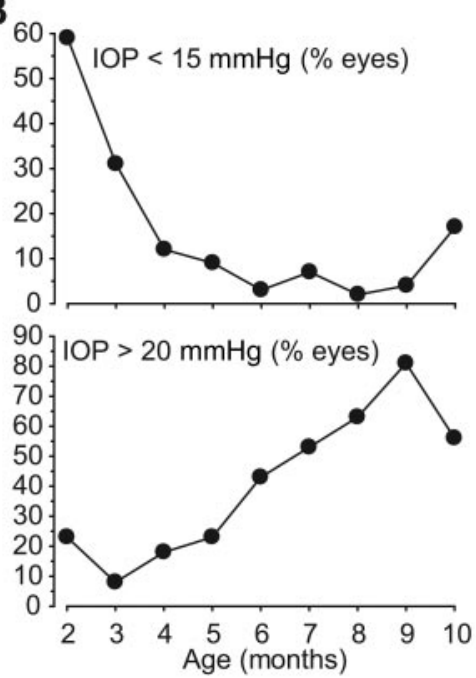

individual nerves, with no systematic difference between age groups $(P=0.08)$. Accordingly, the distribution of total axon number by age in Figure $6 \mathrm{~A}$ follows the trend for axon density in Figure 5A: There are fewer total axons in the old high-IOP nerves than in the old low-IOP nerves $(P=0.04)$, whereas the young high-IOP nerves had fewer axons than the old low-IOP nerves $(P=0.02)$. Plotting total axon number against mean lifetime IOP (Fig. 6B) shows that mean lifetime IOP is also a good predictor of total axon number $\left(r^{2}=-0.53, P=0.003\right)$. As with axon density, the young high-IOP nerves have a number of axons similar to that of the old high-IOP nerves $(P=$ 0.52), owing to their similar IOP. Thus, for both axon density (Fig. 5B) and number (Fig. 6B), mean IOP is a strong predictive factor. This is reflected in the positive correlation between axon total and axon density in Figure $6 \mathrm{C}\left(r^{2}=0.60, \mathrm{P} \ll\right.$ 0.001 ). Figure $6 \mathrm{C}$ includes additional data from the young normal group (Table 1). The mean axon density for these four eyes was $5.5 \pm 0.2 \times 10^{5}$ axons $/ \mathrm{mm}^{2}$, which is statistically different from the mean for the two eyes from the young high-IOP group $(P=0.005)$. Similarly, the total number of axons in the nerves from the young normal group is approximately $25 \%$ more ( 4.06 vs. $3.1 \times 10^{4}$ axons; $P=0.008$ ) than the number in the young high-IOP nerves.

\section{Pressure and Corneal Thickness}

Figure 7 depicts cross sections through the limbic region of the anterior segment in four DBA/2 mice. In a young normal animal
(Table 1), the cornea was $49.1 \pm 1.0 \mu \mathrm{m}$ thick and clearly delineated the anterior component of an open, iridocorneal angle (Fig. 7A). In contrast to the healthy young normal thin cornea was the grossly thickened cornea $(115 \pm 1.0 \mu \mathrm{m}$ thick) from a young high-IOP mouse (mean IOP: $19.62 \pm 1.06 \mathrm{~mm}$ $\mathrm{Hg}$; Fig. $7 \mathrm{~B}$ ). In an old low-IOP DBA/2 mouse (mean IOP: $19.0 \pm 0.7 \mathrm{~mm} \mathrm{Hg}$ ), the cornea was slightly thicker $(57.5 \pm 2.4$ $\mu \mathrm{m}$; Fig. $7 \mathrm{C}$ ) than the young normal cornea in Figure $7 \mathrm{~A}$. There are also signs of iris dispersion contributing to what we interpret as modest angle closure. Finally, for an old high-IOP animal with a lifetime average IOP well above the colony mean for that age $(26.7 \pm 0.3 \mathrm{~mm} \mathrm{Hg})$, the cornea is much thicker (93.1 $\pm 1.9 \mu \mathrm{m}$; Fig. 7D). Accompanying the higher pressures in this animal is a severely atrophied iris that effectively closes the iridocorneal angle.

Figure $7 \mathrm{E}$ illustrates the mean corneal thickness for the mice in Table 1 whose IOPs were measured. This graph reinforces the point that it is not necessarily age that determines corneal thickness. The mean corneal thickness in the old high-IOP animals was similar to that in the young high-IOP eyes $(P=$ 0.11 ) - both roughly $110 \mu \mathrm{m}$. In stark contrast, the corneas of the old low-IOP mice were more than $35 \%$ thinner than those of the old high-IOP eyes, a significant difference $(P=0.005)$ despite the proximity in age between these groups. Similarly, the difference between the young high-IOP and old low-IOP corneas is also significant $(P=0.006)$. Again, the corneal thickness differences correlate with differences in mean IOP 


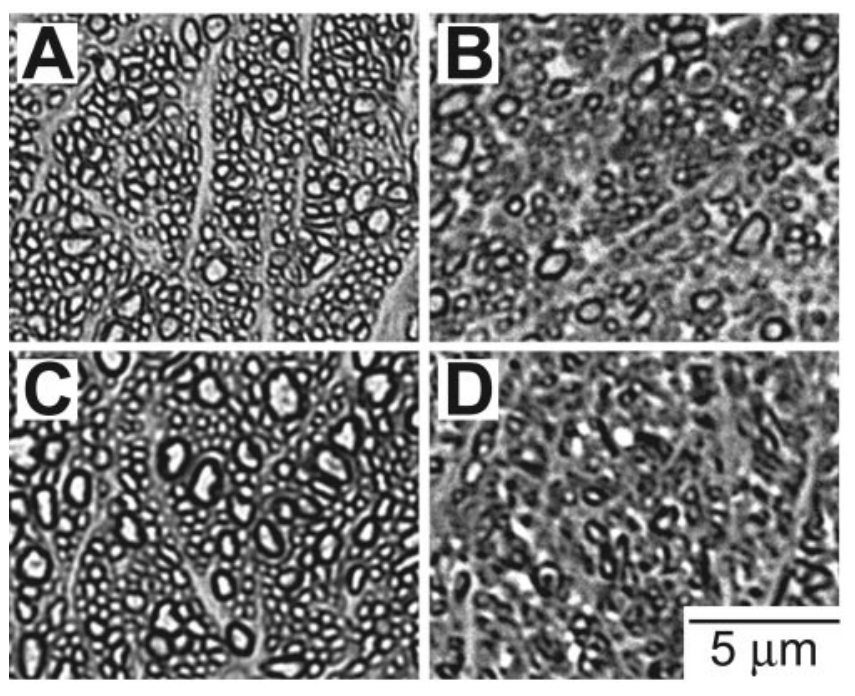

FIGURE 4. High-magnification light photomicrographs of cross sections through DBA/2 optic nerve. (A) Optic nerve of a young normal $\mathrm{DBA} / 2$ (designated as nondiseased in Table 1) with thin, clear cornea and absence of iris atrophy demonstrated dense axonal packing $(5.4 \times$ $10^{5}$ axons $/ \mathrm{mm}^{2}$ ) and normal myelination. (B) Nerve of a young highIOP animal with a mean IOP $(21.60 \pm 1.14 \mathrm{~mm} \mathrm{Hg})$ above the colony average for that age showed disorganized axon fascicles, vacuolization, and fewer myelin profiles. Axon density $=3.5 \times 10^{5}$ axons $/ \mathrm{mm}^{2}$. (C) Nerve from an old low-IOP DBA/2 with lower than average IOP $(19.80 \pm 2.23 \mathrm{~mm} \mathrm{Hg})$ showed no extant signs of axon degeneration. Axon density $=6.2 \times 10^{5}$ axons $/ \mathrm{mm}^{2}$. (D) Nerve of an old high-IOP animal (mean IOP: $25.06 \pm 2.38 \mathrm{~mm} \mathrm{Hg}$ ) demonstrated severe atrophy and axonal dropout. Axon density $=2.6 \times 10^{5}$ axons $/ \mathrm{mm}^{2}$.

between the groups. Figure $7 \mathrm{~F}$ demonstrates that corneal thickness-as with axon density and axon total (Figs.5B, 6B)tended to increase with increasing mean lifetime IOP $\left(r^{2}=\right.$ $0.61, P=0.04)$. The similarly thick corneas in young and old high-IOP eyes accompanies their similar IOPs, whereas the old low-IOP eyes cluster near the thin-cornea/low-IOP portion of the scatterplot (Fig. 7F).

\section{Corneal Damage in the DBA/2 Mouse}

Mindful of our own and others' observations regarding corneal calcification on DBA/2 eyes, ${ }^{9}$ it was important to know whether applanation tonometry with the Tono-Pen (Medtronic Solan) damages the cornea in any way or could be causal in the corneal thickening observed in DBA/2 eyes. Using eyes from mice representing a range of ages that had never been measured with the tonometer, we observed no qualitative difference in the appearance or extent of corneal occlusions when compared with mice that had monthly tonometer measurements (Fig. 8A-D). In some cases, (e.g., the 11-month DBA/2 in Fig. 8D) mice that had never experienced applanation tonometry had more severe corneal abnormalities than mice with 8 months of IOP readings (13-month DBA/2 in Fig. 8C), including severe neovascularization. It is possible the Tono-Pen may exacerbate the corneal changes, but evidence indicates that corneal thickening is part of the normal aging process in the $\mathrm{DBA} / 2$ mouse. Figure $8 \mathrm{C}$ documents the iris atrophy and pigment dispersion phenotype, typical of $\mathrm{DBA} / 2$ anterior chamber changes (note the thinned, nonpigmented iris).

\section{Corneal Thickness as a Predictor of Axonal Density}

Measurements of corneal thickness in Figure $7 \mathrm{~F}$ demonstrate a positive correlation with mean IOP. That axon density de- creases with increasing mean IOP (Figs. 5B) suggests that increasing corneal thickness ought to predict fewer axons. Indeed, the scatterplot in Figure 9 indicates that axonal density declined dramatically with increasing corneal thickness, with a strong negative correlation $\left(r^{2}=-0.75, P \ll 0.001\right)$. Comparing Figure 9 with Figure $7 F$, in which corneal thickness is plotted against mean lifetime IOP, shows that reduced axon density and thickening of the cornea are both associated with higher IOP. For example, old high-IOP eyes demonstrated the fewest axons and thickest corneas, corresponding to their higher mean IOPs (Fig. 2B). The old low-IOP eyes had thinner corneas and correspondingly higher axonal density. Additional data from the young normal eyes (Table 1) are also included in this plot (Fig. 9). These eyes differed from the young high-IOP eyes, in that their corneas were significantly thinner (66.2 \pm $6.8 \mu \mathrm{m}$ vs. $111.4 \pm 4.7 \mu \mathrm{m} ; P=0.01)$. Of interest is the statistical similarity in both axonal density $(P=0.92)$ and corneal thickness $(P=0.81)$ between the young normal and old low-IOP eyes.
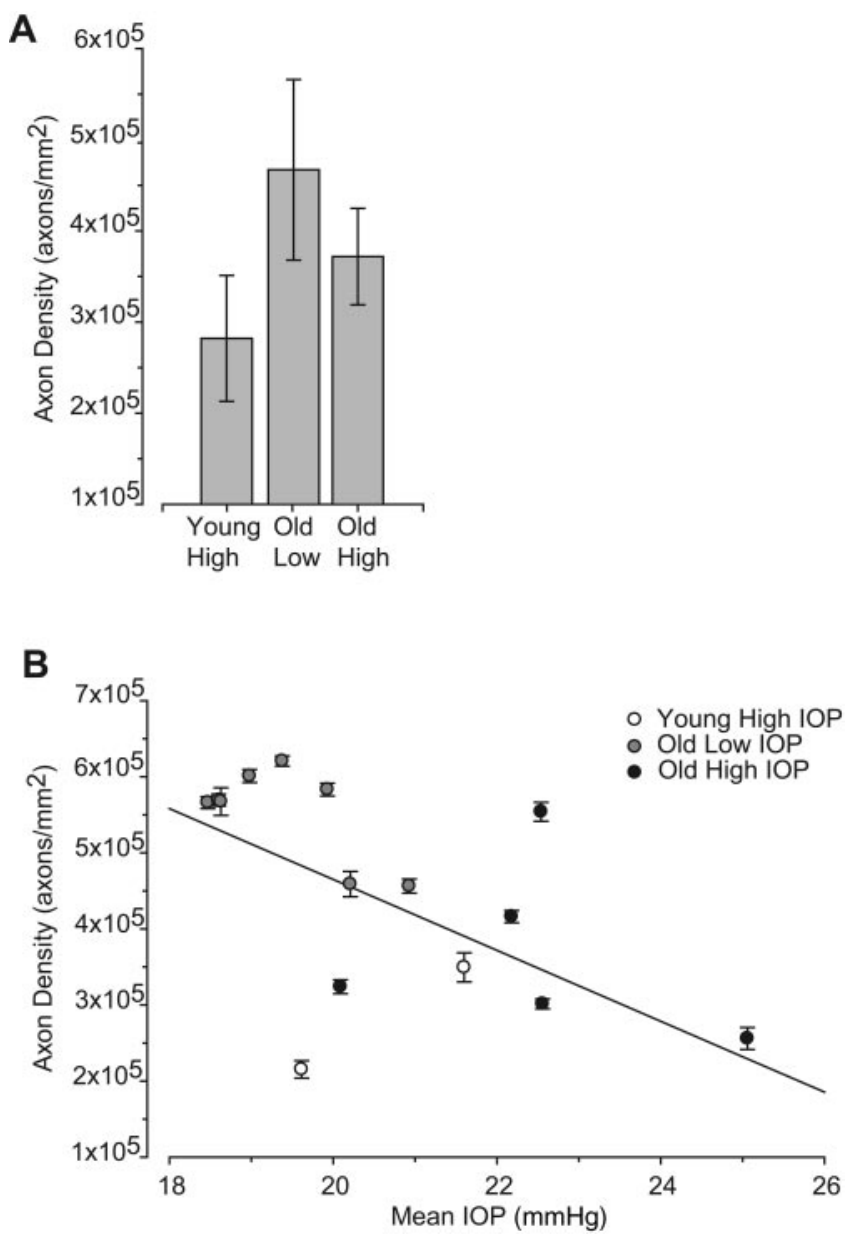

Figure 5. (A) Axon density measured in 12 separate nerves from DBA/2 animals whose IOP was measured (summarized in Table 1). Densities are shown for young high-IOP $\left(2.8 \pm 0.6 \times 10^{5}\right.$ axons $\left./ \mathrm{mm}^{2}\right)$, old low-IOP $\left(4.7 \pm 1.0 \times 10^{5}\right.$ axons $\left./ \mathrm{mm}^{2}\right)$, and old high-IOP $(3.7 \pm$ $0.5 \times 10^{5}$ axons $/ \mathrm{mm}^{2}$ ) mice. Optic nerve axon density is approximately $25 \%$ less for the old high-IOP mice compared with the old low-IOP mice $(P=0.004)$, and young high-IOP nerves had axon density nearly $40 \%$ lower than the old low-IOP nerves $(P=0.001)$. (B) Axon density decreased with increasing mean IOP, regardless of age $\left(r^{2}=-0.72, P \ll 0.001\right)$. 

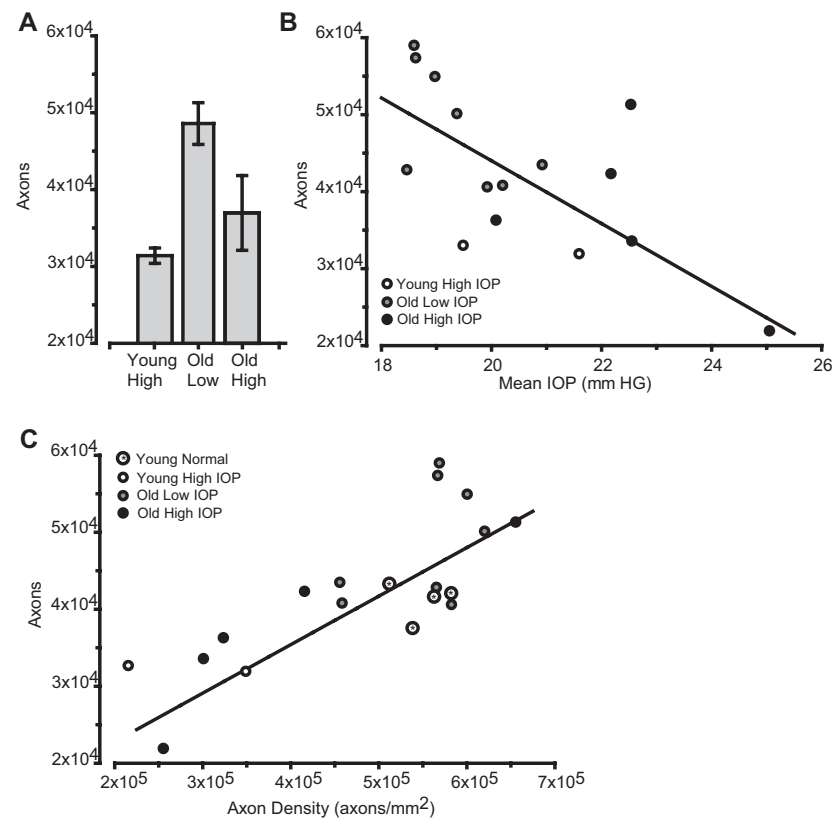

FIGURE 6. (A) Total number of axons measured in optic nerves of the mice summarized in Table 1 . Mean number of axons in young high-IOP mice was $3.1330 \pm 0.0530 \times 10^{4}$; in old low-IOP mice, $4.8583 \pm$ $0.2711 \times 10^{4} ;$ and in old high-IOP mice, $3.7019 \pm 0.4863 \times 10^{4}$. There were fewer axons in old high-IOP optic nerve than the old low-IOP nerve $(P=0.04)$ and fewer axons in young high-IOP optic nerve than old low-IOP nerve $(P=0.02)$. (B) The number of axons decreased with increasing mean IOP $\left(r^{2}=-0.53, P=0.003\right)$. The absence of error bars for total axons is a consequence of estimating the total from a single cross-sectional area of each nerve. (C) Strong correlation between axonal number and density across ages $\left(r^{2}=0.60, P \ll 0.001\right)$. Circled asterisks: data from young normal eyes in Table 1.

\section{Discussion}

\section{Significant IOP Increase in DBA/2}

Our study is the first in which IOP has been monitored longitudinally and correlated with multiple histopathological features in the DBA/2 mouse. The longitudinal data show an increase in IOP between two and 10 months of age that is approximately linear (slope $=0.9 \mathrm{~mm} \mathrm{Hg} / \mathrm{mo}$; Fig. 2). These data are the best-defined IOP change reported in a large population of DBA/ 2 mice and also describe the earliest reported significant increase in IOP in this particular glaucoma model. We found the earliest colony average IOP to be 15 to $16 \mathrm{~mm}$ $\mathrm{Hg}$ at 2 months of age, increasing to approximately $19 \mathrm{~mm} \mathrm{Hg}$ at 6 months. By 8 months, colony average IOP rose to $21 \mathrm{~mm}$ $\mathrm{Hg}$ and peaked at almost $23 \mathrm{~mm} \mathrm{Hg}$ at 10 months. However, contrary to a previous study, ${ }^{9}$ we did not observe a gender difference in IOP.

The Tono-Pen XL tonometer (Medtronic Solan) was designed for measuring human IOP, but it has been shown to be an effective, efficient method to obtain IOP in rodents. ${ }^{20,15}$ The Tono-Pen was the only noninvasive method of IOP measurement available at the time these studies were initiated. As reported earlier ${ }^{15}$ (Inman DM et al., manuscript submitted), we found that multiple averaged measurements allowed a degree of confidence in the obtained IOP. The Tono-Pen is effective at registering drug-induced decreases or increases in IOP (Inman DM et al., manuscript submitted), an observation that also confirmed its practicality for measuring mouse IOP. IOP as measured by Tono-Pen in normal $\mathrm{C} 57 \mathrm{Bl} / 6$ mice averaged $12.36 \pm 0.32 \mathrm{~mm} \mathrm{Hg} .{ }^{15}$ Many mouse studies in which IOP was measured with methods other than the Tono-Pen have been published. A servo-null micropipette system found IOP in black Swiss outbred mice to be $17.8 \pm 0.4 \mathrm{~mm} \mathrm{Hg}{ }^{21}$ Rebound tonometry in $\mathrm{C} 57 \mathrm{Bl} / 6$ mice found an average IOP of $9.8 \pm 3.9$ $\mathrm{mm} \mathrm{Hg},{ }^{22}$ and the Goldmann applanation tonometer, when applied to $\mathrm{C} 57 \mathrm{Bl} / 6$ mouse eyes, averaged $13.7 \pm 3.2 \mathrm{~mm} \mathrm{Hg}{ }^{23}$ The range of IOP in C57Bl/6 mice across these various methods is 9.8 to $17.8 \mathrm{~mm} \mathrm{Hg}$, and the value obtained using the TonoPen was $12.4 \mathrm{~mm} \mathrm{Hg},{ }^{15}$ placing the Tono-Pen squarely within the range of these other methods.

A thorough survey of IOP in several mouse strains using a direct cannulation method found an almost two-fold range in normal IOP, including 3- to 4-month-old DBA/2 mice with an average IOP of $11.697 \pm 0.022 \mathrm{~mm} \mathrm{Hg} .{ }^{24}$ A separate study of the iris pigment dispersion and iris atrophy phenotype in the DBA/2 monitored IOP at 3, 6, 9, and 19 months of age. ${ }^{9}$ The IOP at 3 months averaged $\sim 12 \mathrm{~mm} \mathrm{Hg}$, but a gender difference became apparent by 6 months of age, with male IOP at $9.4 \pm$ $0.4 \mathrm{~mm} \mathrm{Hg}$ and female IOP at $13 \pm 0.9 \mathrm{~mm} \mathrm{Hg}$. By nine months, male IOP was $16.2 \pm 1.4 \mathrm{~mm} \mathrm{Hg}$ and female IOP was $20.3 \pm 1.8 \mathrm{~mm} \mathrm{Hg} .{ }^{9}$ Our IOPs were from 1 to $6 \mathrm{~mm} \mathrm{Hg}$ higher at each age point in comparison to the other report of DBA/2 IOP. 9 The consistency of our data across a large number of animals reveals that the Tono-Pen is precise, but not necessarily accurate.

Elsewhere, we have compared our tonometer measurements with IOP established invasively by cannulation (Inman DM, et al., manuscript submitted). These data indicate a high correlation between the Tono-Pen and cannulation $(r=0.80$, $P<0.001)$. Reitsamer et al. ${ }^{15}$ compared IOP in mice by using the Tono-Pen and the servo-null micropipette and found no difference between the two methods. In addition, a strong correlation $(r=0.97)$ between the Tono-Pen and cannulationdetermined IOP was found in eyes with pressure that was step raised by changing the height of a saline reservoir connected by cannula to the posterior chamber. ${ }^{15}$ The data in this study document an almost $7-\mathrm{mm} \mathrm{Hg}$ increase in IOP from 2 to 10 months for the colony (Fig. 2A), a seemingly modest change, but one that is highly significant because of the volume of data.

\section{Elevations in IOP as a Predictor of Axonal Loss in $\mathrm{DBA} / 2$}

Our studies demonstrate that the Tono-Pen successfully detects IOP change within individual animals and that these readings correlate strongly with optic nerve pathology (Figs. 5-7). The Tono-Pen allowed us to monitor change in IOP, especially through its ability to reveal significant increases in colony average IOP from month to month (Figs. 2, 3). Moreover, chronic increases in IOP of 5 to $6 \mathrm{~mm} \mathrm{Hg}$ are sufficient to induce significant reduction in the number of axons (Figs. 5B, 6B). Each of the histopathological changes observed in optic nerve reinforced the observation that differences in mean lifetime IOP are a critical determinant for disease. For example, both axon density and number were significantly different between groups of old mice with significantly different mean lifetime IOP (Figs.5B, 6B). Whereas chronic IOP elevation led to loss of myelinated axons, as evidenced by the old high-IOP DBA/2 animals with greater than $50 \%$ axon loss in the optic nerve (Fig. 5), analysis of two young high-IOP animals (Fig. 2B) helped demonstrate that mean lifetime IOP is a better predictor of axonal disease than age (Figs. 5B, 6B). Thus, a 4-month $\mathrm{DBA} / 2$ mouse with high IOP can exhibit axonal disease to the same degree as a 10-month DBA/2. Our analysis indicates that even within the old low-IOP and old high-IOP groups, modest increases in mean lifetime IOP can lead to significant decreases in axon density and number (Figs. 5B, 6B).

Our axon number calculations corroborate findings of Jeon et al. ${ }^{25}$ who observed an average of $4.44 \times 10^{4}$ axons in the 
FIGURE 7. Photomicrographs of 1to $2-\mu \mathrm{m}$-thick cross sections through the limbic region of the anterior segment of the DBA/2 mouse, showing cornea, iris, ciliary body (CB), and iridocorneal angle (dashed arrow). (A) Limbic region of a young normal mouse that lacked iris atrophy or other pathologic features associated with increased IOP. Solid arrows: the portion of the cornea from which thickness measurements were derived. Corneal thickness measurement in this eye was $49.1 \pm 1.0 \mu \mathrm{m}$. (B) Young high-IOP DBA/2 (mean IOP: $19.62 \pm 1.06 \mathrm{~mm} \mathrm{Hg}$ ) demonstrates pigment dispersion, closure of the iridocorneal angle, and corneal thickening. (C) Old low-IOP DBA/2 (mean IOP: $18.98 \pm 0.70 \mathrm{~mm} \mathrm{Hg}$ ) shows the beginnings of iridocorneal angle closure and thickening of the cornea. Corneal thickness measurement in this eye was $57.5 \pm 2.4 \mu \mathrm{m}$. (D) An old high-IOP mouse (mean IOP: $26.69 \pm 0.26 \mathrm{~mm} \mathrm{Hg}$ ) also demonstrates severe iris atrophy, pigment dispersion and corneal thickening. Corneal thickness measurement in this eye was $93.1 \pm 1.9 \mu \mathrm{m}$. (E) Corneal thickness for young highIOP $(111.4 \pm 4.7 \mu \mathrm{m})$, old low-IOP $(68.6 \pm 5.5 \mu \mathrm{m})$, and old high-IOP $(106.9 \pm 7.6 \mu \mathrm{m}) \mathrm{DBA} / 2$ mice from Table 1 . The average corneal thickness in the old low- and old high-IOP DBA/2 eyes are significantly different. (F) Corneal thickness correlates with mean IOP $\left(r^{2}=0.61, P=0.04\right)$.
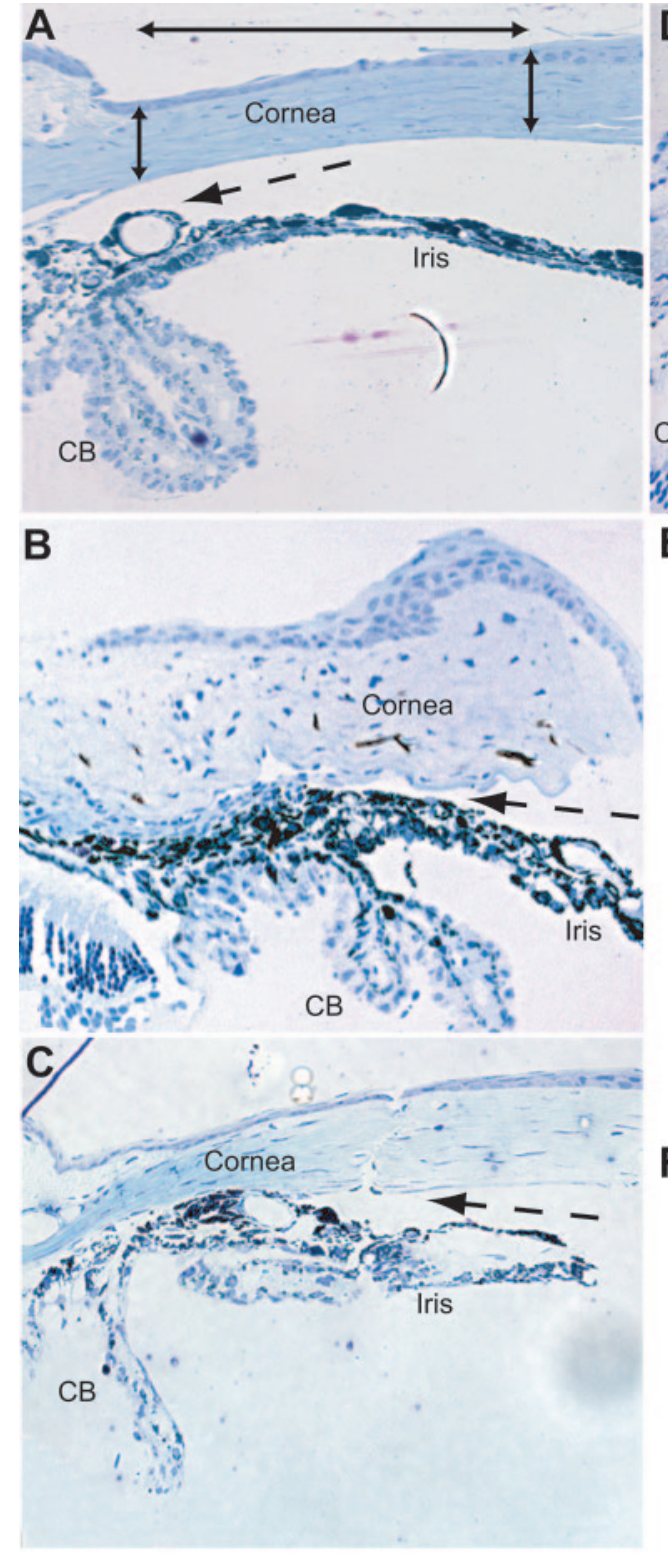

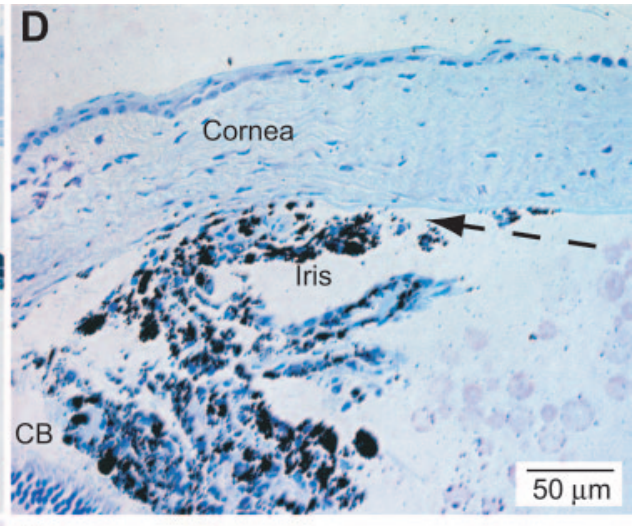

E
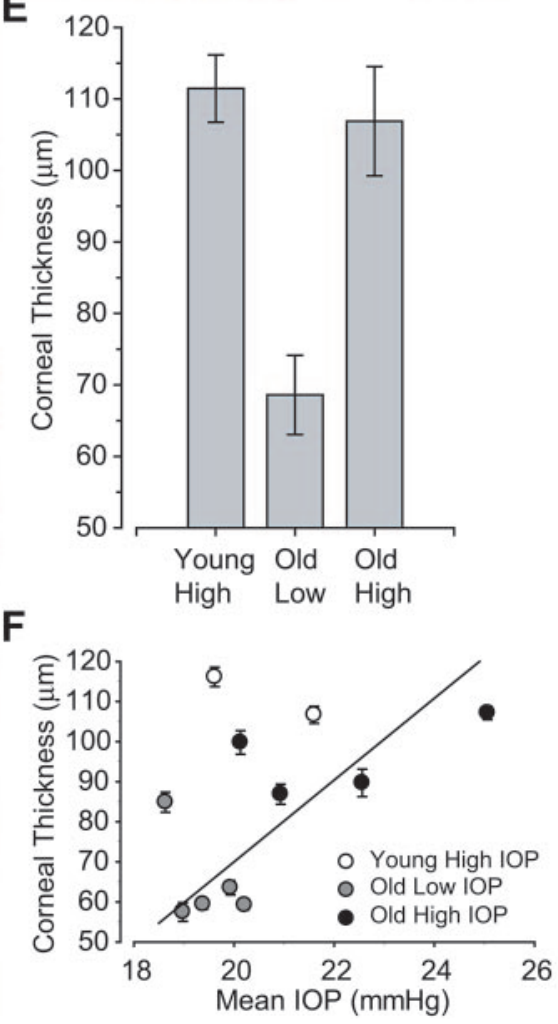

optic nerve, as estimated from sampling electron micrographs. A study performed in a similar manner found $5.46 \times 10^{4}$ axons in optic nerves of $\mathrm{C} 57 \mathrm{Bl} / 6$ mice. $^{26}$ These findings compare well with our data showing that young normal DBA/2 mice without any signs of corneal or iris disease (Table 1) had $4.06 \times 10^{4}$ axons. In an acute mouse model of glaucoma in which the limbus was laser photocoagulated, the number of optic nerve axons in control animals was in the range of $5.7 \times$ $10^{4}$ axons, while mice with raised IOP (44\% greater than control for an average of 7 weeks) had greater than a $50 \%$ decrease in the number of axons. ${ }^{27}$ We observed up to a $50 \%$ loss of myelinated axons in old high-IOP DBA/2 mice with chronically elevated IOP compared with old low-IOP mice (Figs. 5B, 6B). This finding echoes the magnitude of change in axon density in the acute laser coagulation study ${ }^{27}$ and confirms the negative effect chronic IOP elevation has on axon survival in the optic nerve.

Although there can be considerable individual variation, IOP increases with age in most DBA/2 mice (Fig. 3). However, axon counts allowed us to observe that age-related increases in IOP do not wholly dictate nerve disease. Young high-IOP mice could have fewer axons in optic nerve than old low-IOP DBA/2 mice (Figs. 5, 6). One explanation is that the younger mouse with increased IOP and significant axon loss experienced the equivalent of chronically elevated IOP by having a shorter but more dramatic increase. Along these lines, acute models of glaucoma in which IOP can be manipulated precisely have used the "IOP integral," a measure that is calculated by taking the integral of IOP over time, with pressure exposure expressed as mm Hg-days. ${ }^{28}$ The IOP integral correlates well with axon loss and also describes a damage threshold $(200 \mathrm{~mm}$ Hg-days) beyond which axon loss is very rapid in the earliest interval of exposure to high IOP. ${ }^{28}$ In these models, optic nerve axon loss is related to both the magnitude and duration of IOP elevation. ${ }^{28,29}$ In a rat acute glaucoma model, a 10-mm $\mathrm{Hg}$ increase in IOP for 11 days led to axonal degeneration in $10 \%$ of the optic nerve. If the IOP increase went as high as 28 $\mathrm{mm} \mathrm{Hg}$ over 11 days, degenerated axons were found in $100 \%$ of the optic nerve. ${ }^{29}$ The DBA/2 model has relatively low IOP elevation, but for older mice, the duration is significant. We must note that our IOP measurements for the animals compared histologically were not sufficiently frequent to calculate a meaningful IOP integral (Table 1). 

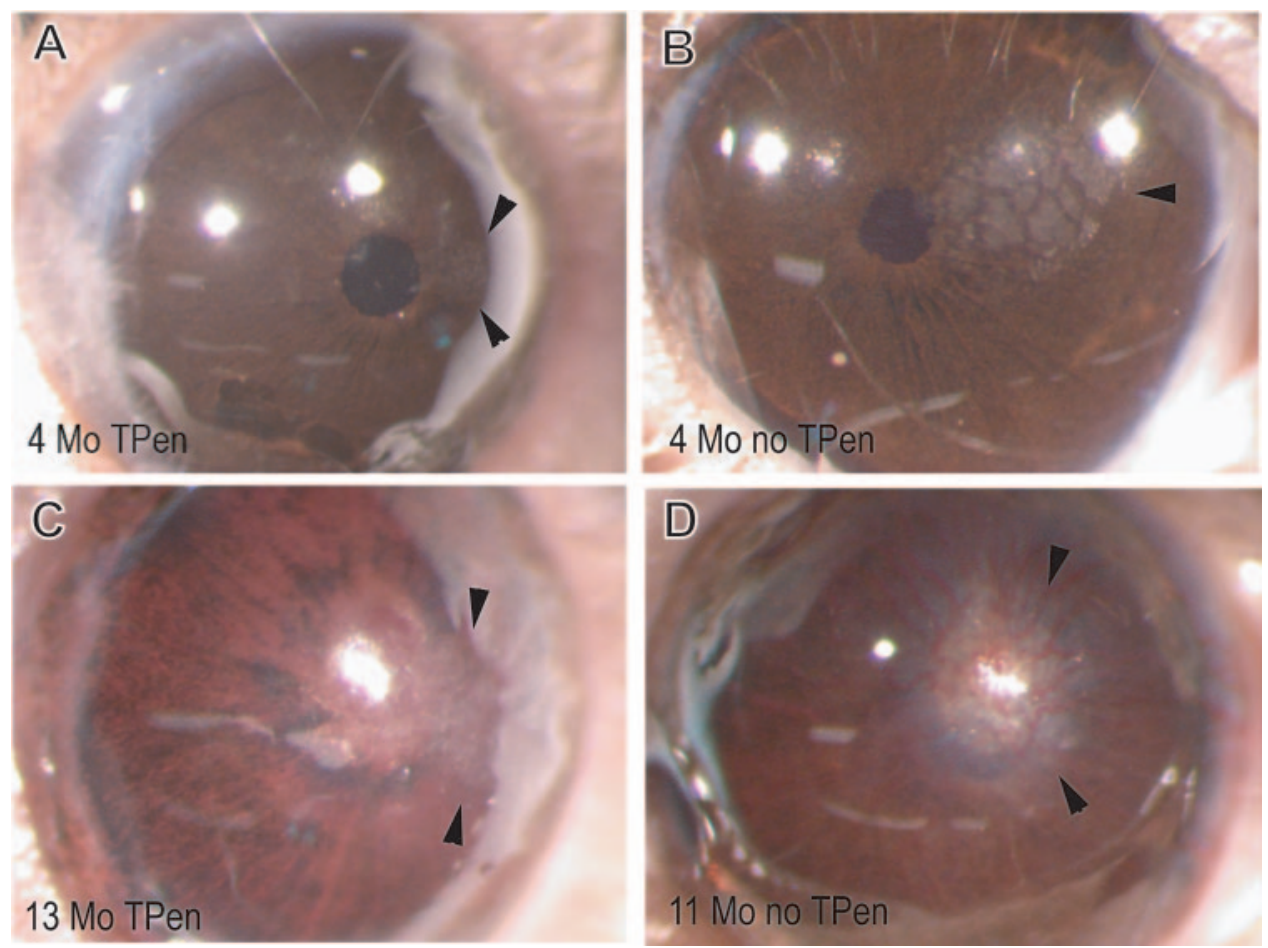

FIGURE 8. Photographs of DBA/2 cornea and iris, showing corneal calcification early and with increasing severity over time, regardless of whether IOP was measured. (A) A 4-month-old DBA/2 cornea with a small cluster of corneal calcification (arrowbeads). IOP was measured with the Tono-Pen (Medtronic Solan) in this mouse once a month for 2 months before this photograph was obtained. (B) A 4-month DBA/2 mouse with no tonometry history. Arrowbead: cluster of corneal calcification. (C) A 13-month DBA/2 with 8 months of tonometer measurements and corneal calcification (arrowheads). Iris atrophy and pigment dispersion were evident in this eye in the thinning and nonpigmented areas of the iris. Note the thickened ring of pigment around the pupil. (D) An 11-month DBA/2 mouse with no history of IOP measurement. This mouse had corneal calcification (arrowbeads) and severe neovascularization within the cornea (red vessels across the eye).
We did not assess regional loss of axons, though acute models of glaucoma in the rat ${ }^{29}$ and mouse ${ }^{27}$ demonstrate that axon loss occurred preferentially in the superior half of the optic nerve, a pattern of loss also recorded in humans. ${ }^{30-32}$ Observing that a young $\mathrm{DBA} / 2$ mouse with high IOP can exhibit advanced optic neuropathy reinforces the necessity of determining the earliest glaucoma-related changes, to elucidate the disease mechanism. This determination is particularly necessary for the DBA/2 model, in which onset of disease is variable. This variability of onset is unlike acute models of glaucoma, but is akin to the variable onset in the human population.

\section{Cornea Thickness as a Predictor of Axon Density}

We observed that increased corneal thickness also depended on mean lifetime IOP (Fig. 7F). Thus, the old low-IOP animals

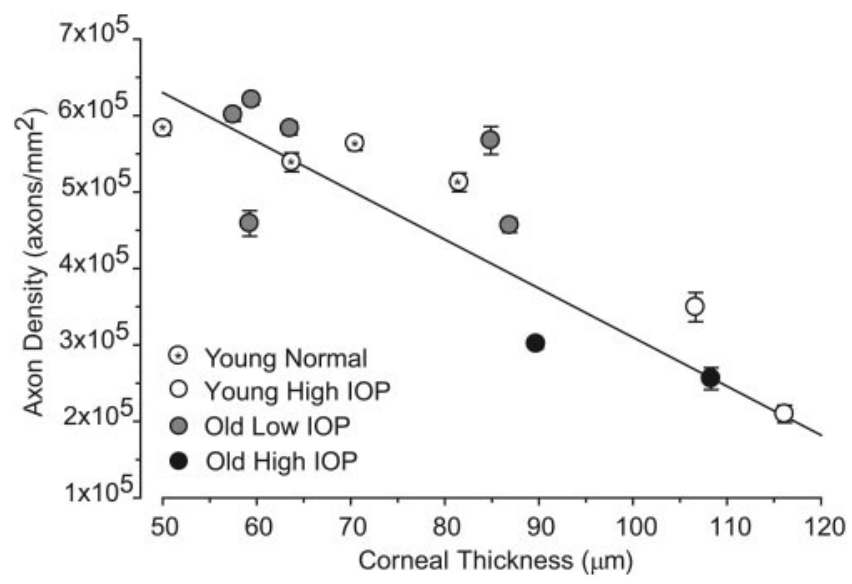

FIGURE 9. Scatterplot demonstrating that corneal thickness is a good predictor of axonal density for the three age groups analyzed in our study $\left(r^{2}=-0.75, P \ll 0.001\right)$. Circled asterisks: Data from the 4-month-old nondiseased eyes in Table 1. had thinner corneas than did either the old or young high-IOP animals. Surprisingly, corneal thickness predicted axonal loss in the DBA/2 mouse: Thicker corneas correlated with lower axon density (Fig. 9). Even within an age group, small differences in corneal thickness correlated with differences in axon density. The scatterplot showing axon density by corneal thickness showed data from young normal mice (Table 1) that fell along the regression line, but for which no IOP data had been obtained. These eyes had both higher axon density and number than the two young high-IOP eyes in Figure 2B. The corneas of these young normal eyes were also interspersed among the thinnest from our study (Fig. 9), comparable to those of the old low-IOP eyes (Fig. 2B).

These data suggest that the relationship between corneal thickness and retinal health in the DBA/2 mouse was very different from the observations regarding corneal thickness and glaucoma in the human. Observations from patient data suggest that thick corneas would correlate with axon preservation, not axon loss, because a subgroup of patients with POAG who had thicker corneas had better vision, better cupto-disc ratio, and used fewer medications to control their glaucoma than POAG patients with thinner corneas. ${ }^{6}$ Thin corneas in patients with POAG also correlate with greater visual field loss. ${ }^{7,33}$ Unfortunately, the histologic processes underlying the observed increases in corneal thickness are beyond the scope of the present paper. To our knowledge, a similar study of corneal thickness and axon density has not been undertaken in humans, because it would require postmortem comparisons of anterior chamber and optic nerve, probably well after the degeneration of the optic nerve had any meaningful variation. An indirect indication of axon number (nerve fiber layer thickness) measured in healthy subjects showed no correlation with central corneal thickness, ${ }^{34}$ but patients with ocular hypertension and thin corneas had significantly thinner retinal nerve fiber layers. ${ }^{35}$ A different picture of the significance of central cornea thickness emerges when one considers patients with PACG. In these patients, the greatest corneal thickness is found in cases of acute glaucoma characterized by (among other 
things) decreased visual acuity, corneal edema, IOP greater than $40 \mathrm{~mm} \mathrm{Hg}$, and completely closed angle on gonioscopy. ${ }^{8}$ Unlike PACG, the DBA/2 mouse is a model of chronic secondary angle-closure glaucoma, for which surgery does not reverse the acute vision loss in PACG. It is evident that IOP can be affected by central corneal thickness, but how is corneal thickness related to axonal loss in glaucoma? It may be that corneal changes are a side effect of the disease. Patients with acute PACG who have the thickest corneas also had the lowest density of corneal endothelial cells, ${ }^{8}$ a condition some believe can exacerbate corneal edema. Endothelial cell density has not been studied in the $\mathrm{DBA} / 2$, but corneal edema is likely to be significant in these mice, given the incidence of corneal occlusions, ulceration, ${ }^{9,11}$ and inflammation. ${ }^{10}$ The intriguing relationship between corneal changes and axon loss in the DBA/2 optic nerve requires additional study.

There are numerous advantages to an acute model, not least of which is the control over timing and severity of injury parameters. The DBA/2 is a model in which chronic IOP elevation more closely resembles the human condition, a situation that may be beneficial for examining subtle modifiers of glaucoma development. From our initial examination of this model, we have determined that DBA/2 mice undergo a significant increase in IOP beginning as early as 2 months (Figs. 2A, $3 \mathrm{~A})$. Mean IOP over time strongly predicts axonal loss in the optic nerve. Our data demonstrate that noninvasive measurement of IOP in the DBA/2 mouse can be used for positive discrimination between mice with ongoing axonal disease and their healthy litter mates. These methods could be important for optimizing future studies of disease or therapeutic intervention in the DBA/2 mouse. A good example of this optimization is the IOP-based selection of DBA/2 mice that was undertaken for the whole-retina microarray study accompanying this report. ${ }^{36}$ In that study, mice were selected at various ages based on similar IOP measurements. The resultant microarray data had so little variability across samples that, in a 40,000-gene array, expression of only 68 genes was modulated. Selecting mice based on IOP probably influenced the signal uniformity across samples.

\section{Acknowledgments}

The authors thank Alisson K. Stephen and Holly M. Finkel for expert technical assistance in obtaining IOP measurements from the DBA/2 colony.

\section{References}

1. Flanagan JG. Glaucoma update: epidemiology and new approaches to medical management. Ophthalmic Physiol Opt. 1998;18:126132.

2. Gordon MO, Beiser JA, Brandt JD, et al. The Ocular Hypertension Treatment Study: baseline factors that predict the onset of primary open-angle glaucoma. Arch Ophthalmol. 2002;120:714-720; discussion 829-730.

3. Kerrigan-Baumrind LA, Quigley HA, Pease ME, Kerrigan DF, Mitchell RS. Number of ganglion cells in glaucoma eyes compared with threshold visual field tests in the same persons. Invest Ophthalmol Vis Sci. 2000;41:741-748.

4. Brandt JD. The influence of corneal thickness on the diagnosis and management of glaucoma. J Glaucoma. 2001;10(suppl 1):S65S67.

5. Copt RP, Thomas R, Mermoud A. Corneal thickness in ocular hypertension, primary open-angle glaucoma, and normal tension glaucoma. Arch Ophthalmol. 1999;117:14-16.

6. Herndon LW, Weizer JS, Stinnett SS. Central corneal thickness as a risk factor for advanced glaucoma damage. Arch Ophthalmol. 2004;122:17-21.

7. Jonas JB, Stroux A, Velten I, Juenemann A, Martus P, Budde WM. Central corneal thickness correlated with glaucoma damage and rate of progression. Invest Ophthalmol Vis Sci. 2005;46:12691274 .

8. Sihota R, Lakshmaiah NC, Titiyal JS, Dada T, Agarwal HC. Corneal endothelial status in the subtypes of primary angle closure glaucoma. Clin Exp Ophthalmol. 2003;31:492-495.

9. John SW, Smith RS, Savinova OV, et al. Essential iris atrophy, pigment dispersion, and glaucoma in $\mathrm{DBA} / 2 \mathrm{~J}$ mice. Invest Ophthalmol Vis Sci. 1998;39:951-962.

10. Sheldon WG, Warbritton AR, Bucci TJ, Turturro A. Glaucoma in food-restricted and ad libitum-fed DBA/2NNia mice. Lab Anim Sci. 1995; 45:508-518.

11. Schuettauf F, Rejdak R, Walski M, et al. Retinal neurodegeneration in the DBA/2J mouse-a model for ocular hypertension. Acta Neuropathol (Berl). 2004;107:352-358.

12. Danias J, Lee KC, Zamora MF, et al. Quantitative analysis of retinal ganglion cell (RGC) loss in aging DBA/2NNia glaucomatous mice: comparison with RGC loss in aging C57/BL6 mice. Invest Ophthalmol Vis Sci. 2003;44:5151-5162.

13. Moore CG, Milne ST, Morrison JC. Noninvasive measurement of rat intraocular pressure with the Tono-Pen. Invest Ophthalmol Vis Sci. 1993;34:363-369.

14. Thanos S, Naskar R. Correlation between retinal ganglion cell death and chronically developing inherited glaucoma in a new rat mutant. Exp Eye Res. 2004;79:119-129.

15. Reitsamer HA, Kiel JW, Harrison JM, Ransom NL, McKinnon SJ. Tonopen measurement of intraocular pressure in mice. Exp Eye Res. 2004;78:799-804.

16. Chang B, Smith RS, Hawes NL, et al. Interacting loci cause severe iris atrophy and glaucoma in DBA/2J mice. Nat Genet. 1999;21: 405- 409 .

17. Anderson MG, Smith RS, Hawes NL, et al. Mutations in genes encoding melanosomal proteins cause pigmentary glaucoma in DBA/2J mice. Nat Genet. 2002;30:81-85.

18. Sappington RM, Pearce DA, Calkins DJ. Optic nerve degeneration in a murine model of juvenile ceroid lipofuscinosis. Invest $O p h$ thalmol Vis Sci. 2003;44:3725-3731.

19. Calkins DJ, Sappington RM, Hendry SH. Morphological identification of ganglion cells expressing the alpha subunit of type II calmodulin-dependent protein kinase in the macaque retina. J Comp Neurol. 2005;481:194-209.

20. Pang IH, Wang WH, Cameron Millar J, Clark AF. Measurement of mouse intraocular pressure with the Tono-Pen. Exp Eye Res. 2005; 81:359-360

21. Avila MY, Carre DA, Stone RA, Civan MM. Reliable measurement of mouse intraocular pressure by a servo-null micropipette system. Invest Ophthalmol Vis Sci. 2001;42:1841-1846.

22. Danias J, Kontiola AI, Filippopoulos T, Mittag T. Method for the noninvasive measurement of intraocular pressure in mice. Invest Ophthalmol Vis Sci. 2003;44:1138-1141.

23. Cohan BE, Bohr DF. Measurement of intraocular pressure in awake mice. Invest Ophthalmol Vis Sci. 2001;42:2560-2562.

24. Savinova OV, Sugiyama F, Martin JE, et al. Intraocular pressure in genetically distinct mice: an update and strain survey. BMC Genet. 2001;2:12.

25. Jeon CJ, Strettoi E, Masland RH. The major cell populations of the mouse retina. J Neurosci. 1998;18:8936-8946.

26. Williams RW, Strom RC, Rice DS, Goldowitz D. Genetic and environmental control of variation in retinal ganglion cell number in mice. J Neurosci. 1996;16:7193-7205.

27. Mabuchi F, Aihara M, Mackey MR, Lindsey JD, Weinreb RN. Regional optic nerve damage in experimental mouse glaucoma. Invest Ophthalmol Vis Sci. 2004;45:4352-4358.

28. McKinnon SJ. Glaucoma: ocular Alzheimer's disease? Front Biosci. 2003;8:s1140-1156.

29. Morrison JC, Moore CG, Deppmeier LM, Gold BG, Meshul CK, Johnson EC. A rat model of chronic pressure-induced optic nerve damage. Exp Eye Res. 1997;64:85-96.

30. Quigley HA, Green WR. The histology of human glaucoma cupping and optic nerve damage: clinicopathologic correlation in 21 eyes. Ophthalmology. 1979;86:1803-1830. 
31. Quigley HA, Addicks EM, Green WR, Maumenee AE. Optic nerve damage in human glaucoma. II. The site of injury and susceptibility to damage. Arch Opbthalmol. 1981;99:635649.

32. Anderson DR. What happens to the optic disc and retina in glaucoma? Ophthalmology. 1983;90:766-770.

33. Kim JW, Chen PP. Central corneal pachymetry and visual field progression in patients with open-angle glaucoma. Opbthalmology. 2004;111:2126-2132.
34. Iester M, Mermoud A. Retinal nerve fiber layer and physiological central corneal thickness. J Glaucoma. 2001;10:158-162.

35. Henderson PA, Medeiros FA, Zangwill LM, Weinreb RN. Relationship between central corneal thickness and retinal nerve fiber layer thickness in ocular hypertensive patients. Opbthalmology. 2005;112:251-256.

36. Steele MR, Inman DM, Calkins DJ, Horner PJ, Vetter ML. Microarray analysis of retinal gene expression in the DBA/2J model of glaucoma. Invest Opbthalmol Vis Sci. 2006;47:977-985. 